\title{
APLICAÇÃO DO ÍNDICE DE CONCENTRAÇÃO DA RUGOSIDADE DO RELEVO NO ENTENDIMENTO DO NÍVEL DE EXPOSIÇÃO DOS SISTEMAS CÁRSTICOS OCORRENTES NA REGIÃO NORTE DO MUNICÍPIO DE CURITIBA, PR
}

\author{
Edenilson Roberto do Nascimento \\ Departamento de Geologia - Universidade Federal do Paraná - Campus Centro politécnico - Rua Francisco H. dos \\ Santos 100 - Jardim das Américas - CEP 81531-980 - Curitiba,PR - Caixa postal 19.011 - e-mail: deni_ern@ufpr.br \\ José Manoel dos Reis Neto \\ Departamento de Geologia - Universidade Federal do Paraná - Campus Centro politécnico - Rua Francisco H. dos \\ Santos 100 - Jardim das Américas - CEP 81531-980 - Curitiba,PR - Caixa postal 19.062 - e-mail: jmreis@ufpr.br
}

Antonio Manuel de Almeida Rebelo

Av. Arthur da Silva Bernardes, 1514 - Bairro Portão - CEP 80320-300 - Curitiba,PR -

e-mail: rebelo_antonio@hotmail.com

\begin{abstract}
Resumo
Apresenta-se os resultados da aplicação do Índice de Concentração da Rugosidade (ICR) do relevo no entendimento e caracterização do nível de exposição dos sistemas cársticos ocorrentes na região norte do município de Curitiba, Estado do Paraná. A área estudada abrange sistemas cársticos encaixados em metadolomitos do Grupo Açungui, aflorantes em diferentes subbacias hidrográficas, de distintos compartimentos geomorfológicos da zona limítrofe entre as bacias dos rios Iguaçu e Ribeira. Feições endocársticas (cavernas e abismos) estão expostas somente em áreas da bacia do Alto Ribeira, enquanto feições exocársticas (dolinas, poljes e uvalas) são comuns às duas bacias, porém mais características das sub-bacias do Alto Iguaçu. A aplicação do Estimador de Kernel permitiu a análise da concentração espacial do parâmetro morfométrico ICR do relevo em toda a área estudada. A individualização dos dados, para cada sub-bacia, permitiu associar os sistemas cársticos de maior grau de exposição às sub-bacias cujo relevo apresenta os maiores índices de concentração da rugosidade. Verificou-se que, apesar dos diferentes sistemas cársticos compartilharem uma origem e evolução comuns, até o Mioceno Inferior, os atuais níveis de exposição, nas diferentes sub-bacias, são o registro da erosão diferencial que afetou mais intensamente os metadolomitos nas sub-bacias do Alto Ribeira, a partir daquela época geológica. Tais resultados permitem concluir que mesmo áreas com os mesmos padrões geológicos e climáticos podem desenvolver e exibir diferentes feições cársticas em níveis altimétricos correlatos, desde que em distintos compartimentos geomorfológicos. Por fim, o parâmetro enfocado constitui-se numa ferramenta de estudo consistente e ágil, pela sua capacidade diagnóstica e pela facilidade de sua utilização em sistemas de informações georreferenciadas.
\end{abstract}

Palavras-chave: Carste, Compartimentos geomorfológicos, Rugosidade do relevo.

\begin{abstract}
Here are presented the results of applying the relief Roughness Concentration Index (RCI) in understanding and characterizing of the exposure levels of the karst systems that occur in the northern region of the city of Curitiba, State of Paraná. The study
\end{abstract}


area covers karst systems embedded in metadolomites of the Açungui Group, outcropping in different hydrographic subbasins, in different geomorphologic compartments of the zone between the basins of rivers Iguaçu and Ribeira. Endokarstic features (caves and pits) are exposed only in areas of the Alto Ribeira basin, while exokarstic features (dolines, polje and uvalas) are common to both basins, but more characteristic of the Alto Iguaçu sub-basin. The application of the Kernel Estimator allowed an analysis of the spatial concentration of the relief's morphometric ICR parameter throughout the study area. The individualization of data for each sub-basin allowed the association of the karst systems with higher exposure levels to those sub-basins whose relief had the highest roughness concentration. It was found that, although the different karst systems share a common origin and evolution until the Lower Miocene, the current exposure levels in the different sub-basins are the records of differential erosion that affected more intensely the metadolomites at the Alto Ribeira's sub-basins from that geological period on. Such results indicate that even areas with the same geological and climatic patterns can develop and display different karst features correlated to altitudinal levels, provided they belong to different geomorphological compartments. Finally, the parameter that was focused is a consistent and agile study tool, due to its diagnostic ability and ease of use in geo-referenced information systems.

Keywords: Karst, Geomorphological compartments, Relief roughness.

\section{Introdução}

Este trabalho apresenta os resultados da aplicação do Índice de Concentração da Rugosidade (ICR) do relevo no entendimento e caracterização do nível de exposição dos sistemas cársticos ocorrentes na região norte do município de Curitiba, Estado do Paraná (Figura 1).

A área de estudo está inserida numa região densamente povoada e com grande tradição na mineração de calcário. O conhecimento preciso da ocorrência, distribuição e do funcionamento dos sistemas cársticos aí ocorrentes, torna-se fator fundamental para o planejamento adequado de uma ocupação ordenada do território.

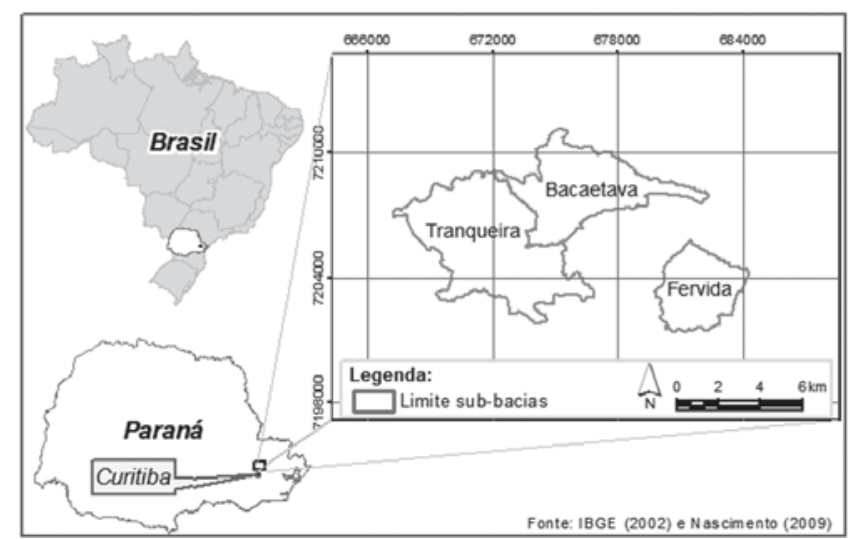

Figura 1 - Localização da área estudada.

As características litoestruturais, climáticas e geomorfológicas da Região Metropolitana de Curitiba, sobretudo a norte do referido município, condicionaram a formação e preservação, em inúmeras áreas, de feições cársticas superficiais (exocársticas) e subterrâneas (endocársticas) em metadolomitos da Formação Capiru (Grupo Açungui). As oscilações climáticas cenozóicas proporcionaram um ambi- ente favorável ao desenvolvimento da erosão química dos litotipos em questão. A instalação das drenagens sobre e no interior dos metadolomitos, comumente nas posições menos elevadas do relevo, devido a condições estruturais, permitiram, também, uma considerável atuação de processos físi$\cos$.

Diversos trabalhos abordaram o carste da Região Metropolitana de Curitiba (RMC), dedicados, principalmente, ao estudo das características hidrogeológicas, geotécnicas e ambientais, visando a explotação do aquífero carste regional. Dentre outros, se destacam Bonacim (1996), Lisboa (1997) e Hindi (1999), que descrevem e quantificam o modo de funcionamento do aquífero. E, Silva \& Oka-Fiori (1996), que mapeou e analisou os traços gerais da geomorfologia, hidrografia e dos aspectos litoestruturais relacionados com as feições cársticas ocorrente na região de Tranqueira, município de Almirante Tamandaré-PR.

A existência de contextos comuns de evolução dos sistemas cársticos, de toda a Região Metropolitana de Curitiba, e áreas adjacentes, foi identificada por Rebelo et al (2007), que concluiu por dois períodos principais de carstificação meteórica entre o Cretáceo e o Mioceno Inferior. Nesse contexto, os sistemas cársticos teriam se originado e desenvolvido concomitantemente ao desenvolvimento das superfícies de aplainamento/erosão do Purunã (correlata à Superfície Japi) e do Alto Iguaçu. A partir do Mioceno Inferior, parte das referidas superfícies foram afetadas pela abertura do Vale do Rio Ribeira, enquanto os sistemas cársticos associados eram modificados, ou mesmo destruídos, e novos sistemas gerados, constituindo-se, esta fase de carstificação, na mais recente da região.

A partir da abertura do Vale do Ribeira, inicia-se novo ciclo erosivo caracterizando um novo compartimento geomorfológico, com amplitudes topográficas muito mais pronunciadas que as que distinguem a Superfície do Alto 
Iguaçu, processos estes que afetaram os sistemas cársticos existentes. Verifica-se, atualmente, que os sistemas cársticos existentes na região, embora apresentem um mesmo contexto geológico e climático, distribuem-se por diferentes compartimentos geomorfológicos, drenados pelos tributários dos rios Iguaçu e Ribeira. Conforme Rebelo et al (2007) e Nascimento (2009), em cada um desses compartimentos, os sistemas cársticos apresentam distintos graus de evolução e diferentes níveis de exposição, relação esta que se pretende aprofundar.

Então, neste estudo, com a aplicação do Índice de Concentração da Rugosidade (ICR) do relevo (Hobson, 1972; Sampaio, 2008) no entendimento do nível de exposição dos sistemas cársticos ocorrentes na região, objetiva-se esclarecer alguns aspectos, ainda obscuros, da relação entre a intensidade dos processos erosivos, em um determinado compartimento geomorfológico, e o nível de exposição e de evolução de sistemas cársticos pré-existentes. Objetiva-se, outrossim, testar, em tal contexto, o poder diagnóstico do referido parâmetro morfométrico, como ferramenta na caracterização do relevo, em ambiente de sistemas de informações geográficas (SIG).

\section{Materiais e métodos}

Neste estudo, com a aplicação do Índice de Concentração da Rugosidade (ICR) do Relevo (Hobson, 1972; Sampaio, 2008), objetiva-se esclarecer alguns aspectos, da relação entre a intensidade dos processos erosivos, e o nível de exposição/evolução dos carstes existentes na parte norte da Região Metropolitana de Curitiba.

Neste caso, optou-se por "explorar" o poder diagnóstico do referido índice, pois, embora outros parâmetros morfométricos tenham sido utilizados para caracterizar o relevo da Região Metropolitana de Curitiba (Canali, 1980; Rebelo et al, 2007), o ICR destacou-se por apresentar estreita correlação com o nível de exposição dos sistemas cársticos existentes (Nascimento 2009).

O Índice de Rugosidade de Hobson (1972) consiste em um grid de células dimensionadas pela escala da grade numérica retangular do mapa, apresentando um valor único de rugosidade para cada célula. Ou seja, para cada célula (pixel de 10m, por exemplo), há um índice intrínseco aos $100 \mathrm{~m}^{2}$ de área analisada, sem relação alguma com as células vizinhas. Com base em Hobson (1972), Sampaio (2008) utilizando o "Estimador de Densidade de Kernel" eliminou o inconveniente da classificação pontual do relevo, analisando a concentração espacial da rugosidade e a identificação de unidades morfológicas distintas.

Ferrari et al (1998) ao caracterizar morfométricamente a superfície cárstica do Núcleo Cablocos no Vale do Ribeira, no Estado de São Paulo, com a utilização do Índice de rugosidade (Hobson 1972), sem a utilização do Estimador de Densidade de Kernel identifica o inconveniente da interação entre o número e a magnitude das irregularidades do terreno, que podem apresentar mesmo índice de rugosidade para terrenos com características diferentes, o que não ocorre no índice proposto por Sampaio (2008).

A área estudada, compreende cerca de $444 \mathrm{~km}^{2}$, e foi analisada em duas escalas. Na escala regional, que compreendeu toda a área de ocorrência de metadolomitos, e na escala de sub-bacias, onde foram abordadas individualmente as características do relevo nessas litologias. As sub-bacias objeto de estudo, denominadas de Tranqueira, Fervida e Bacaetava, abrangem os municípios de Almirante Tamandaré, Bocaiúva do Sul, Colombo, Itaperuçu e Rio Branco do Sul e foram selecionadas considerando os seguintes atributos:

(a) situação geográfica na zona limítrofe dos compartimentos geomorfológicos drenados pelos rios Iguaçu e Ribeira;

(b) contexto climático e geológico comum (Grupo Açungui e Formação Serra Geral);

(c) diferentes tipos de feições cársticas: endocársticas (cavernas) e exocársticas (dolinas, poljes, uvalas entre outros) hospedadas exclusivamente em metadolomitos;

(d) distintos graus de exposição dos sistemas cársticos, e

(e) evolução geomorfológica e cárstica comum até o Mioceno Inferior.

Como principais dados, informações e ferramentas de estudo, utilizou-se:

(a) O conjunto de dados altimétricos, geológicos e perfis de poços, disponibilizado pela Companhia de Saneamento do Paraná SA (SANEPAR), sobre o "Aquífero Carste" da RMC, na escala 1: 25.000;

(b) O Cadastro de Cavidades Naturais do Estado do Paraná, fornecido pelo Grupo de Estudos Espeleológicos do Paraná (GEEP-Açungui, 2002);

(c) ICR. Procedeu-se à transformação do grid (pontos representados por "pixels" que possuem um valor de declividade), para um arquivo de pontos amostrais transformados em valores de rugosidade, e, por último, a aplicação do estimador de Kernel ponderado. Foi utilizada a discretização a partir do uso de percentis, para evitar a formação de classes de valores vazias ou espacialmente super/ subdimensionadas, em decorrência da formação de classes com amplitude de dados ou elementos desproporcionais aos demais (Sampaio, 2008). O processo de tratamento e obtenção dos dados em formato grid foi realizado nos softwares do pacote ArcGis 9.3; 
(d) Individualização dos valores de ICR para as áreas da bacia hidrográfica do Alto Iguaçu (BAI), do Alto Ribeira (BAR) e para as áreas de cada sub-bacia. Tal procedimento permitiu gerar dados para caracterização do relevo em escala regional e na escala das sub-bacias que, posteriormente, foram comparados, e

(e) Trabalhos de campo que permitiram coletar dados topográficos e morfológicos das feições cársticas e verificar os resultados obtidos no geoprocessamento e modelagens.

\section{Contexto regional}

\section{Geologia}

De acordo com a figura 2, ocorrem na área estudada as litologias pertencentes às Formações Capiru do Grupo Açungui, do Neoproterozóico, com presença de rochas metadolomíticas e silicáticas cortadas por diques de diabásio de idade Juro-Cretácea da Formação Serra Geral, além de sedimentos quaternários ( SANEPAR, 2006).

Conforme Fiori (1994), há evidências de estruturas resultantes de eventos tectônicos que fraturaram, falharam e dobraram os litotipos da região. Destacam-se na configuração do relevo as estruturas de cavalgamento e os diques de diabásio, constituindo este último, cristas alongadas na direção NW, quando intrudidos em metadolomitos, e vales nesta mesma direção quando intrudidos em litologias mais resistentes ao intemperismo.

Embora estejam em um mesmo ambiente geológico regional, as especificidades de cada sub-bacia, principalmente no que se refere às características estruturais e à disposição litológica, permitem diferentes relações com o sistema de drenagem, resultando em condições específicas à exposição dos sistemas cársticos.

\section{Geomorfologia}

A existência de remanescentes geomórficos de paleosuperfícies de aplainamento/erosão na área estudada é descrita por diversos autores, destacando-se os trabalhos de Maack (1947), Bigarella \& Salamuni (1962), Canali (1982) e Riffel (2005). Os remanescentes atestam um contexto geomorfológico regional comum, onde se desenvolveram sistemas cársticos hoje situados em faixas altimétricas específicas (Rebelo et al., 2007). Com a abertura do Vale do rio Ribeira, a partir do Mioceno Inferior, iniciou-se novo ciclo erosivo regional, que afetou as sub-bacias de Fervida e Bacaetava, drenadas pela BAR. Já a sub-bacia de Tranqueira, drenada pelo Alto Iguaçu, continuou sob ambiente erosivo muito próximo ao que atuou em Bacaetava e Fervida antes da abertura do Vale do Ribeira (Figura 2). Desta forma, o carste desenvolvido em ambiente geológico, geomorfológico e climático uniforme até o Mioceno Inferior, posteriormente foi exposto, nas bacias do Alto Iguaçu (BAI) e do Alto Ribeira (BAR), a diferentes dinâmicas erosivas.

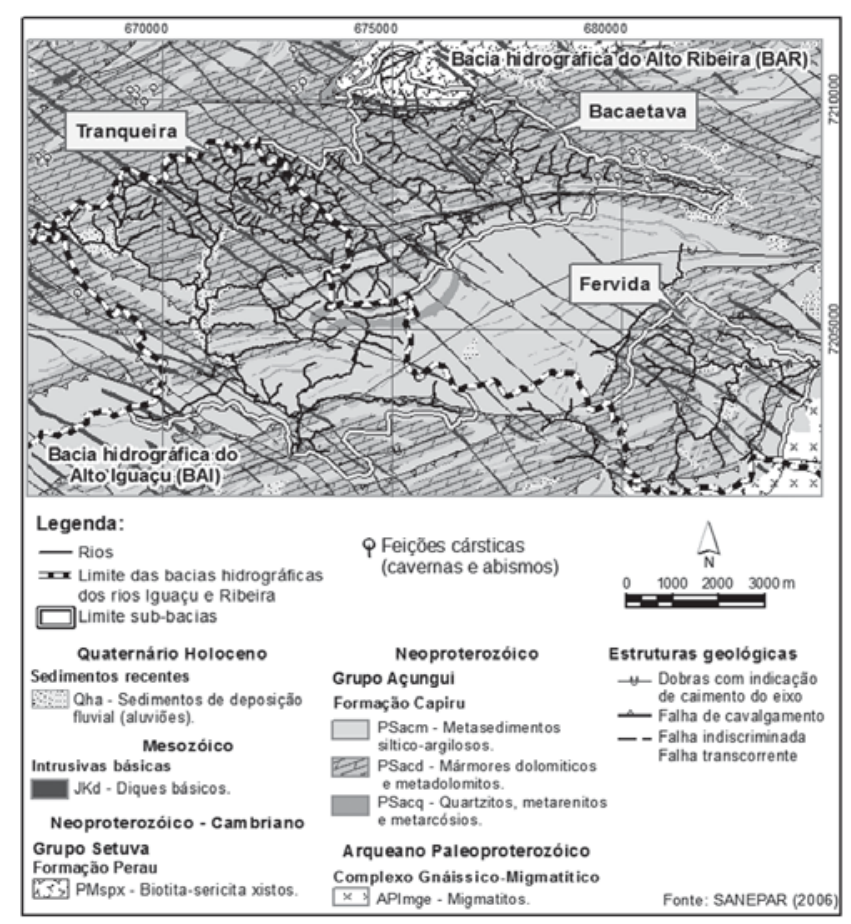

Figura 2 - Contexto geológico e hidrográfico das sub-bacias estudadas.

\section{Hidrografia}

Merece destaque a localização das sub-bacias de Tranqueira, Fervida e Bacaetava, na zona limítrofe da BAI e da BAR. O caráter endorréico da bacia do rio Iguaçu, pertencente às bacias dos rios Paraná e La Plata, condiciona curso de cerca de $1320 \mathrm{~km}$, somente em território paranaense, atravessando praticamente todo o Estado do Paraná. Suas nascentes localizam-se na Serra do Mar, na Região Metropolitana de Curitiba (RMC), em altitudes superiores a 1050m, e sua foz no Rio Paraná, na cota altimétrica próxima de $100 \mathrm{~m}$, o que proporciona gradiente hidráulico de cerca de $0,7 \mathrm{~m} / \mathrm{km}$. Já o sistema hidrográfico do Ribeira, desde as nascentes localizadas a norte de Curitiba até o Oceano Atlântico, no Estado de São Paulo, estende-se por cerca de $350 \mathrm{~km}$, e possui gradiente hidráulico de aproximadamente $3 \mathrm{~m} / \mathrm{km}$, quase quatro vezes maior.

\section{Evolução geomorfológica e exposição dos sistemas cársticos}

A abertura do Vale do rio Ribeira, a partir do Mioceno Inferior, permitiu as condições necessárias para o avanço das cabeceiras de drenagens, e a consequente captura de áreas inseridas em outros sistemas hidrográficos. A erosão remontante das cabeceiras de drenagem truncou sistemas 
cársticos com evolução geológico/geomorfológica comum, em períodos diferentes. Neste modelo, pode-se admitir que as áreas que hospedam aquíferos cársticos na BAI possuem seus correlatos por vezes desmantelados, ou em fase de desmantelamento, na BAR (Figura 3).

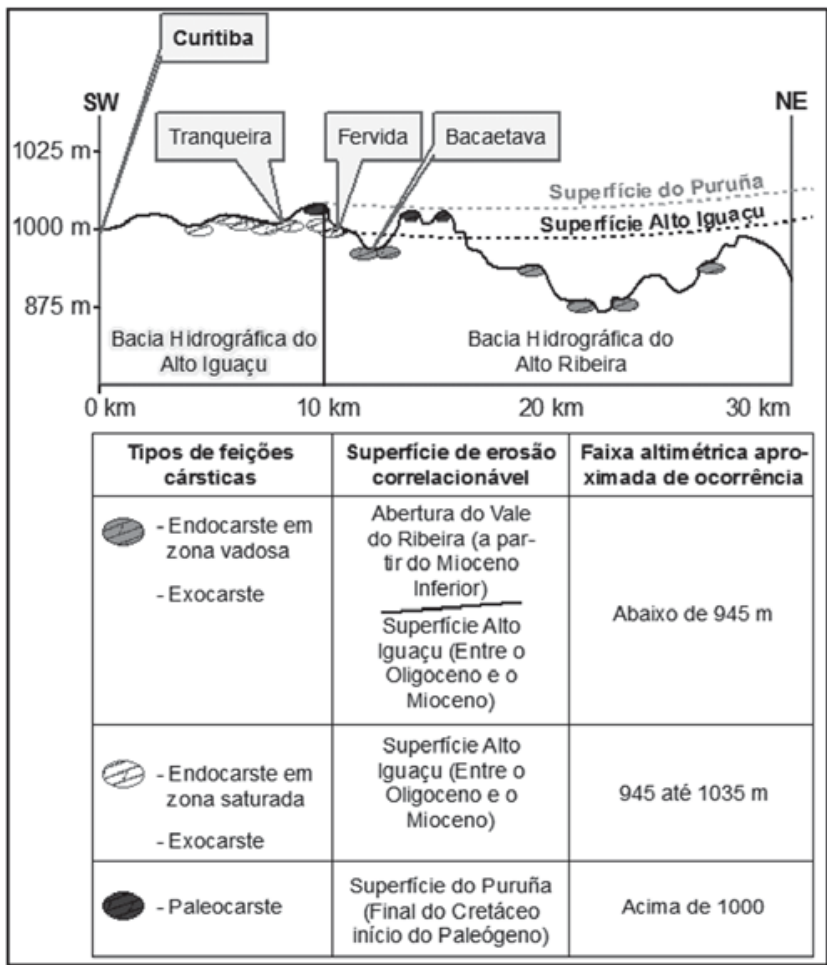

Figura 3 - Perfil esquemático apresentando a faixa altimétrica de ocorrência dos sistemas cársticos e a superfície de erosão correlacionável.

A sub-bacia de Fervida possui algumas características que denotam sua inserção recente na BAR. Entre elas destacam-se: (a) a presença de remanescentes geomorfológicos descritos por Canali (1980) como "colos elevados" (windgaps), que testemunham a erosão de cabeceira e reversões de redes de drenagem da BAI para a BAR e, (b) amplos vales secos no alto curso. A captura implicou mudança do regime erosivo, impondo sobre o carste preteritamente desenvolvido, sob o regime mais ameno da BAI, uma dinâmica hidrogeomorfológica mais pronunciada.

A paisagem gerada pelo avanço da erosão remontante sobre o maciço metadolomítico aponta para um estágio intermediário de exposição dos sistemas cársticos da sub-bacia de Fervida, em relação às sub-bacias de Bacaetava e Tranqueira, com a existência de feições exocársticas e diversas fontes cársticas "ferventes". Estas últimas, muitas vezes, resultam da incisão vertical de canais de drenagem que truncam os condutos cársticos e/ou auxiliam as águas sob pressão através da cobertura inconsolidada. Segundo Hindi (1997), há cerca de 20 fontes cársticas na sub-bacia de Fervi- da, sendo 12 descritas como "ferventes" e 8 como de "fraturas", todas com controle estrutural dado por diques de diabásio.

Na sub-bacia de Bacaetava, observa-se um relevo mais movimentado e um nível maior de exposição dos sistemas cársticos, com ocorrência de feições endocársticas em zona vadosa (cavernas) e exocársticas (dolinas), sugerindo inserção anterior no sistema hidrográfico da BAR em relação à de Fervida.

As características do relevo da sub-bacia de Bacaetava permitem a identificação de três compartimentos de relevo (Figura 4), com feições cársticas características. O primeiro, localizado no baixo curso do rio Bacaetava, é caracterizado por relevo bastante dissecado, com amplitude altimétrica de $227 \mathrm{~m}$, incipiente ocorrência de feições exocársticas e presença de três das cinco cavernas existentes.

O segundo, localizado no médio curso, apresenta relevo mais plano em relação ao compartimento 1 , com amplitude altimétrica de $80 \mathrm{~m}$, onde coexistem dolinas, cavernas e protocavernas. Chama à atenção a ocorrência de cavernas no limite com o baixo curso, próximo às barreiras litoestruturais impostas pelos diques de diabásio, o que aponta para o início do desmantelamento do sistema aquífero parcialmente preservado a montante.

O terceiro compartimento de relevo, localizado no alto curso do rio Bacaetava, é caracterizado por um relevo semelhante ao encontrado no compartimento 2 (médio curso), porém mais preservado, com vários níveis de base locais impostos por diques e faixas de rochas metassedimentares. As feições cársticas ocorrentes são exclusivamente exocársticas, representadas principalmente por dolinas.

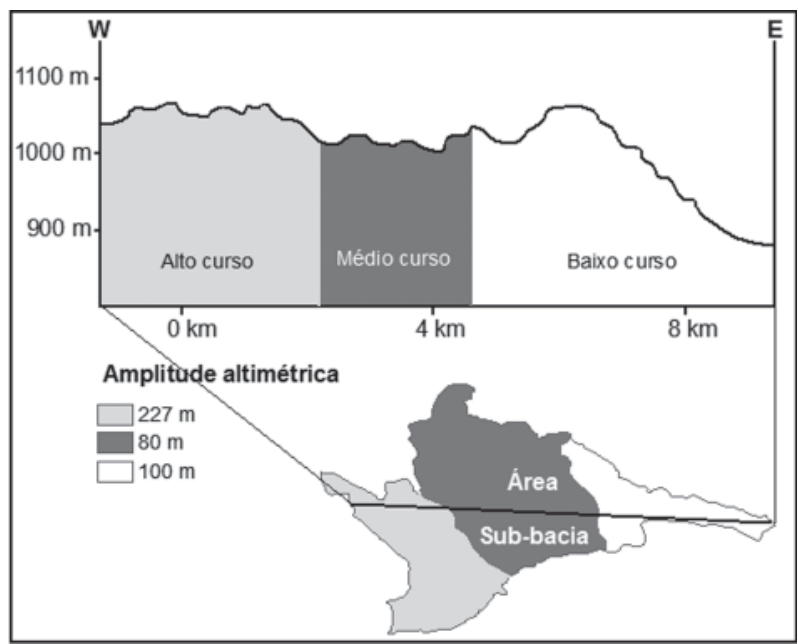

Figura 4 - Perfil topográfico da sub-bacia de Bacaetava, com delimitação de três compartimentos de relevo.

Já na sub-bacia de Tranqueira, o regime erosivo imposto pelo sistema hidrográfico da BAI, menos intenso 
em relação ao atuante no sistema BAR, proporciona dinâmica erosiva diferente da observada em Fervida e Bacaetava. Os metadolomitos estão normalmente em áreas relativamente planas, exceto nas cabeceiras de drenagem, onde há grande densidade de diques de diabásio e faixas quartzíticas em contato com os metadolomitos. As feições cársticas acessíveis são exclusivamente exocársticas, com a presença de endocarste em zona saturada, acessíveis somente por meio da perfuração de poços.

\section{Resultados}

Com a análise do parâmetro morfométrico Índice de Concentração da Rugosidade (ICR) do relevo na área de ocorrência de metadolomitos, foi possível observar que áreas carstificadas com ICR elevados possuem relação direta com a existência de feições endocársticas em zona vadosa (cavernas e abismos).

A figura 5A mostra a distribuição espacial dos intervalos de ICR nos metadolomitos da região estudada, e a localização das feições endocársticas. Os aproximadamente $49 \mathrm{~km}^{2}$ de área de ocorrência de metadolomitos da BAI apresentam $66 \%$ de sua área em intervalos de concentração da rugosidade baixa e muito baixa, com índices entre $1.6 \mathrm{e}$ 12.1, onde ocorrem exclusivamente feições exocársticas. Conforme pode ser observado no gráfico da figura $5 \mathrm{~B}$, o intervalo de concentração de rugosidade média, entre 12.1 e 14.5, abrange $16 \%$ da área, e os intervalos de alta e muito alta concentração da rugosidade cerca de $17 \%$ (índice entre 14.5 e 41.8). Isso proporciona um decréscimo de área concomitante ao aumento do percentual de concentração da rugosidade. Os intervalos de média e alta concentração da rugosidade estão relacionados principalmente às áreas de ocorrência de falhas de cavalgamento e secundariamente à presença de diques de diabásio.

$\mathrm{Na}$ área pertencente à BAR ocorrem cerca de $124 \mathrm{~km}^{2}$ de metadolomitos. Diferentemente BAI, são mais frequentes os intervalos que representam concentrações das rugosidades altas e muito altas (índice entre 14.5 e 41.8 ). Como pode ser observado no gráfico da figura $5 \mathrm{~B}$, há aumento da área abrangida e da quantidade de cavernas e abismos concomitantemente à elevação do percentual de concentração da rugosidade. Quase 50\% dos metadolomitos estão localizados em áreas onde a concentração de rugosidade é alta a muito alta, entre 14.5 e 41.8 , e ocorrem principalmente nos contatos com os diques de diabásio e secundariamente próximos às falhas de cavalgamento. Em alguns casos, nos fundos dos vales. Os intervalos médios entre 12.1 e 14.5 abrangem $22 \%$ da área, enquanto os intervalos entre 1.6e 12.1, que representam áreas de menor concentração da rugosidade, abrangem 29\%, e são representadas principalmente pelos vales (Figura 5B).

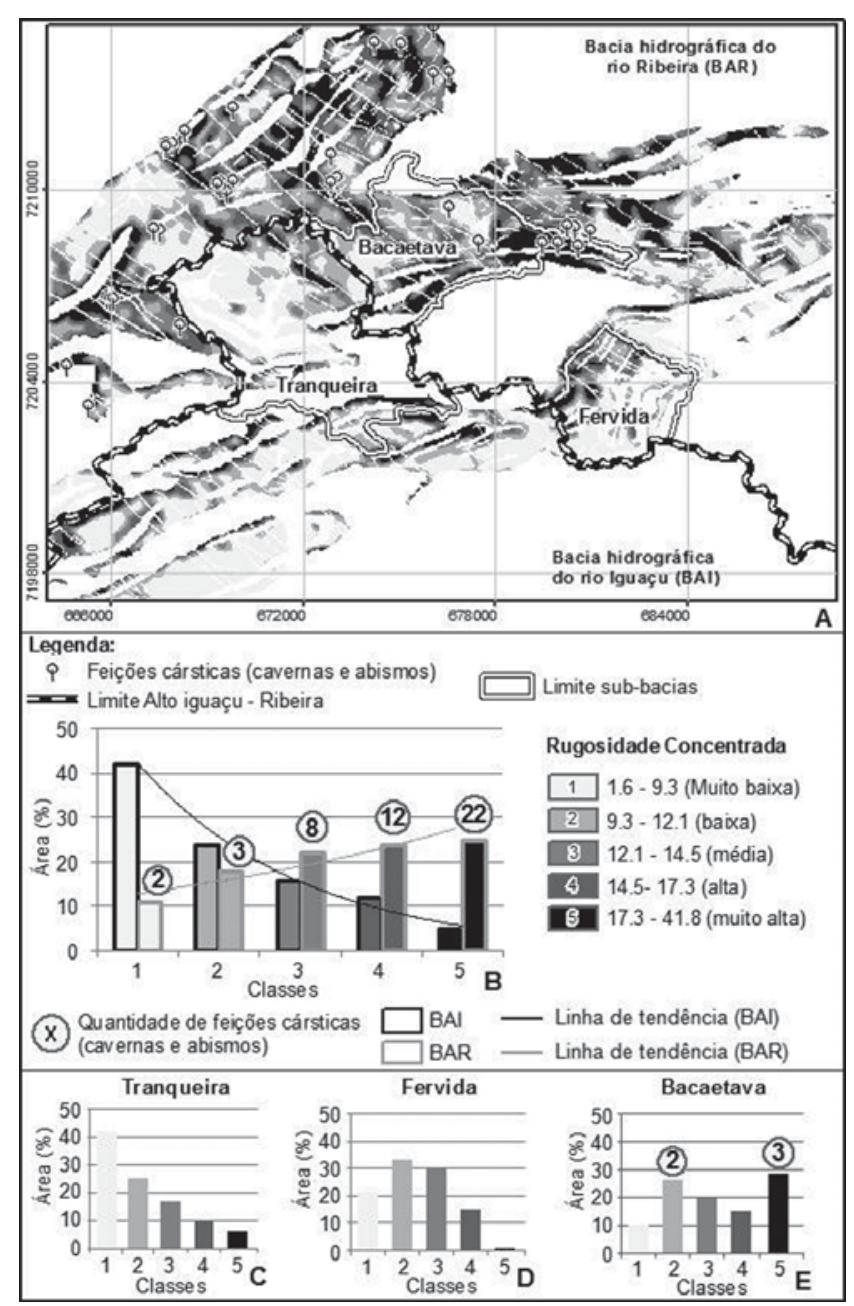

Figura 5 - Distribuição espacial do parâmetro morfométrico Índice de Concentração da Rugosidade (ICR) do relevo em escala regional e de sub-bacias. Os gráficos apresentam a percentagem de área em cada intervalo de rugosidade nas duas escalas de análise.

Os metadolomitos presentes na sub-bacia de Tranqueira possuem cerca de $67 \%$ de sua área entre os intervalos de baixa e muito baixa concentração da rugosidade (índice entre 1.6 e 12.1), que representam as áreas de menor concentração da rugosidade, percentual próximo ao verificado para a BAI nestes intervalos, que é de $66 \%$. Os demais intervalos também são praticamente iguais aos encontrados na BAI, como pode ser observado no gráfico da figura $5 \mathrm{C}$ e na tabela 1 , com diminuição da quantidade de área concomitantemente ao aumento do percentual de concentração da rugosidade. As áreas com concentração da rugosidade incipiente são zonas preferenciais de ocorrência de feições exocársticas, e coincidem geralmente com as áreas de ocorrência da Superfície do Alto Iguaçu. 
Tabela 1 - Percentagem de área por ICR do relevo nas escalas de análise estudadas.

\begin{tabular}{ccccccc}
\hline \multicolumn{7}{c}{ Área $(\%)$} \\
\hline Rugosidade concentrada & BAI & BAR & Tranqueira & Fervida & Bacaetava \\
\hline $1.6-9.3$ (muito baixa) & 30 & 10 & 42 & 21 & 10 \\
$9.3-12.1$ (baixa) & 25 & 16 & 25 & 33 & 26 \\
$12.1-14.5$ (média) & 21 & 24 & 17 & 30 & 20 \\
$14.5-17.5$ (alta) & 15 & 21 & 10 & 15 & 15 \\
$17.5-41.8$ (muito alta) & 9 & 29 & 6 & 1 & 29 \\
\hline
\end{tabular}

De modo similar aos metadolomitos da sub-bacia de Tranqueira, a região de ocorrência de metadolomitos da sub-bacia de Fervida possui percentagens de áreas bastante significativas nos intervalos de muito baixa e baixa concentração da rugosidade, que variam de 1.6 a 12.1 . Entretanto, o acréscimo de área da classe 1 para a 2 mostra existência de relevo um pouco mais rugoso (Figura 5D e Tabela 1), semelhante ao que ocorre na BAR. Já entre o intervalo de concentração da rugosidade média de 12.1 a 14.5 até o intervalo de muito alta concentração da rugosidade de 17.5 a 41.8 , a percentagem de área decresce, a exemplo do que ocorre na BAI. As feições exocársticas ocorrem por praticamente toda a área de ocorrência de metadolomitos, concentrando-se principalmente nas áreas mais planas.

A sub-bacia de Bacaetava possui $44 \%$ de sua área nos intervalos de alta e muito alta concentração da rugosidade, entre 14.5 e 41.8 , concentradas principalmente na porção sul, acompanhando principalmente o vale do rio Bacaetava. A pronunciada ocorrência de áreas com maiores concentrações das rugosidades, como pode ser observado no gráfico da figura 5E e na Tabela 1, segue a linha de tendência observada na BAR. Ali se concentram as áreas de ocorrência de cavernas.

Além da acentuada ocorrência de intervalos de concentração de rugosidade mais elevadas, destaca-se o aumento de área entre as classes de rugosidades muito baixa e baixa (1.6 até 12.1) que, juntas, representam $36 \%$ da área, e se concentram no médio e alto curso do rio Bacaetava, onde ocorrem predominantemente feições exocársticas (Figura 5).

$\mathrm{O}$ aumento de área entre as classes de muito baixa e baixa concentração da rugosidade (1.6 até 12.1), entre as classes de alta e muito alta rugosidade (14.5 até 41.8), acompanha a tendência do gráfico da BAR, porém a diminuição entre as classes de média e alta rugosidade (12.1 até 17.5), acompanha a distribuição verificada na BAI. O gráfico da figura 5D mostra a distribuição, que geometricamente assemelhase ao gráfico de distribuição de área por classe de concentração da rugosidade da sub-bacia de Fervida até o intervalo de alta concentração da rugosidade, porém com forte incremento da área com intervalo de muito alta concentração da rugosidade.

\section{Conclusões}

$\mathrm{Na}$ Bacia do Alto Iguaçu (BAI), onde $66 \%$ da área possui ICR em intervalos de baixa e muito baixa concentração da rugosidade, em superfície ocorrem somente feições exocársticas. $\mathrm{O}$ mesmo fenômeno é verificado na sub-bacia de Tranqueira, que apresenta $67 \%$ de sua área nestes intervalos e nenhuma ocorrência de cavernas e abismos.

Os gráficos que representam a distribuição do ICR por área da BAI e da sub-bacia de Tranqueira possuem distribuição de intervalos semelhante, corroborando a relação existente entre o baixo nível de exposição dos sistemas cársticos e a concentração maior de áreas com muito baixo e baixo ICR.

Na Bacia do Alto Ribeira (BAR), a percentagem de área aumenta concomitantemente ao aumento do ICR, assim como a quantidade de feições endocársticas (cavernas e abismos). Das 47 (quarenta e sete) feições exocársticas cadastradas na região, 2 (duas) ocorrem do intervalo de muito baixa rugosidade, 3 (três) no intervalo de baixa rugosidade, 8 (oito) no de média rugosidade, 12 (doze) no de alta rugosidade e 22 (vinte e duas) no intervalo de muito alta rugosidade.

Também nas sub-bacias de Fervida e Bacaetava é verificado o aumento de exposição dos sistemas cársticos com o aumento da concentração da rugosidade. A sub-bacia de Bacaetava, que possui cerca de $44 \%$ de sua área em intervalos de alta e muito alta concentração da rugosidade, possui 5 (cinco) cavernas; já a sub-bacia de Fervida, que apresenta maior frequência de área nos intervalos de rugosidade baixa e média, apresenta carste em início de processo de exposição, possuindo diversas fontes cársticas surgentes (protocavernas).

Com base nos valores de ICR, pode-se identificar três estágios erosivos do relevo, com diferentes níveis de exposição dos sistemas cársticos, organização espacial e forma de seus componentes, nas sub-bacias estudadas:

(a) O primeiro estágio, identificado na sub-bacia de Tranqueira, única drenada pela BAI, caracteriza-se por um relativo "equilíbrio" entre erosão e as superfícies de aplainamento regionais. Isto permite que os sistemas cársticos estejam em equilíbrio com a paisagem, com feições exocársticas em posição vadosa e endocársticas em posição freática, condições necessárias para o funcionamento e manutenção do "aquífero carste".

(b) O segundo estágio é verificado na sub-bacia de Fervida, onde coexistem feições exocársticas, exposições de condutos cársticos (protocavernas) e feições endocársticas em zona saturada, fato diretamente ligado à captura recente dessa sub-bacia para o sistema hidrográfico do rio Ribeira. Neste estágio o "aquifero cárste" está sendo desmantelado, iniciando-se o alargamento que resultará na exposição de cavernas. 
(c) O terceiro estágio está registrado na sub-bacia do rio Bacaetava, onde a exposição em zona vadosa do endocarste, que preteritamente se encontrava em posição freática, principalmente no baixo e médio curso, condiciona a formação de salões em diferentes níveis, os mais elevados desconectados da rede hidrográfica atual, a exemplo da Caverna de Bacaetava. Nestas condições, o "aquífero carste" já foi totalmente desmantelamento, uma das consequências da atuação dos processos do novo ciclo erosivo vinculado à abertura do Vale do Ribeira.

Assim, a individualização dos dados, para cada subbacia, além de possibilitar a distinção e caracterização dos diferentes estágios do relevo da região estudada, permitiu estabelecer associações sólidas, entre o grau de exposição dos sistemas cársticos com os índices de concentração de rugosidade do relevo das respectivas sub-bacias. Carstes com maior grau de exposição ocorrem em sub-bacias cujo relevo apresenta os maiores índices de concentração da rugosidade do relevo e vice-versa.

Finalmente, é lícito afirmar que o Índice de Concentração da Rugosidade (ICR) do relevo é um parâmetro morfométrico de grande potencial diagnóstico e de fácil utilização em ambiente SIG, sendo eficaz na caracterização do relevo em múltiplas escalas de análise.

\section{Agradecimentos}

Agradecimentos ao LAMIR (Laboratório de Analise de Minerais e Rochas do Departamento de Geologia da UFPR), ao Programa de Pós-Graduação em Geologia da UFPR e à PETROBRAS pelo apoio financeiro.

\section{Referências Bibliográficas}

BIGARELLA, J. J. SALAMUNI, R. Caracteres texturais dos sedimentos da Bacia de Curitiba. Boletim da Universidade Federal do Paraná. Curitiba, v. 7: p. 1-164. 1962.

BONACIM, E. Dinâmica do Sistema Hidrogeológico Cárstico na Área de Tranqueira - Região Metropolitana de Curitiba. 1996. 162f. Dissertação (Mestrado em Geologia) Programa de Pós Graduação em Geologia, Universidade Federal do Paraná, Curitiba.

CANALI, N, E. Contribuição ao estudo da geomorfologia da área de Colombo-PR. 1980. 96f. Dissertação (Mestrado em Geociências) - Universidade de São Paulo, São Paulo.

FERRARI, J. A., HIMURA, S. T., KARMANN, I. Caracterização Morfométrica de uma Superfície Cárstica do Vale do Ribeira, São Paulo (Núcleo Cablocos - PETAR). Revista do Instituto Geológico. São Paulo, v.19, p. 9-17, 1998.

FIORI, A.P. Evolução geológica da bacia Açungui. Boletim Paranaense de Geologia. Curitiba, v. 42, p. 1-27. 1994.
GEEP-Açungui - Grupo de Estudos Espeleológicos do Paraná. Cessão do Cadastro das Cavidades Naturais do Estado do Paraná. Formato shape. Org. Luis Fernando Silva da Rocha. 2002.

HINDI, E. C. Caracterização hidroquímica e hidrogeológica das fontes cársticas das bacias dos rios Tumiri, Água Comprida, Fervida e das Onças - Colombo, PR. 1999. 122f. Dissertação (Mestrado em Geologia) - Programa de Pós Graduação em Geologia da Universidade Federal do Paraná, Curitiba.

HOBSON, R. D. Surface roughness in topography: quantitative approach. In: Chorley (ed.), Spatial analysis in geomorphology. Harper and Row. New York, NY, p. 225245. 1972.

LISBOA, A. A. Proposta de metodologia para avaliação hidrogeológica do Aqüífero Cárstico, Compartimento de São Miguel. 1997. 127f. Dissertação (Mestrado em Geologia) Programa de Pós Graduação em Geologia da Universidade Federal do Paraná, Curitiba.

MAAK, R. Breves notícias sobre a geologia dos estados do Paraná e Santa Catarina. Arquivos do Instituto de Biologia e Pesquisas Tecnológicas. Curitiba, v. 2, p 63-154. 1947.

NASCIMENTO, E. R. Caracterização de feições cársticas a partir de parâmetros morfométricos do relevo: Região Metropolitana de Curitiba (RMC). 2009. 104f. Dissertação (Mestrado em Geologia) - Programa de Pós Graduação em Geologia da Universidade Federal do Paraná, Curitiba.

REBELO, A. M. A., REIS NETO, J. M., BAHNIUK, A. M., NASCIMENTO, E. R.; EEVA, S. T. Sistemas cársticos em rochas metadolomíticas do Grupo Açungui e superfícies de erosão na Região Leste do Estado do Paraná, Brasil. Revista Paranaense de Geociências. No prelo.

RIFFEL, S. B. Curva hipsométrica no mapeamento de paleosuperfícies: Abordagem quantitativa. 2005. 76 f. Dissertação (Mestrado em Geologia) - Programa de Pós Graduação em Geologia da Universidade Federal do Paraná, Curitiba.

SAMPAIO, T. V. M. Parâmetros morfométricos para melhoria da acurácia do mapeamento da rede de drenagem - uma proposta baseada na análise da Bacia Hidrográfica do Rio Benevente - ES. 2008. 147f. Tese (Doutorado em Geografia) - Instituto de Geociências da Universidade Federal de Minas Gerais. Belo Horizonte.

SANEPAR- Cessão de dados geológicos do Aquifero Carste da RMC. Formato shape. 2006.

SILVA, R., OKA-FIORI, C. Estudo das formas cársticas como base para o gerenciamento do uso do manancial subterrâneo na região de Almirante Tamandaré e Rio Branco do Sul - PR. Boletim Paranaense de Geociências. V. 44, p. 59-66. 1996. 